\section{Katharina Inhetveen}

Ludwig Maximilian University of Munich, Germany

\section{Translation Challenges: Qualitative Interviewing in a Multi-Lingual Field}

DOI: https://doi.org/10.18778/1733-8077.8.2.03

Abstract This paper suggests how translation processes can be integrated in qualitative interviews in multi-lingual research fields. While theoretical and methodological problems of language and translation have been thoroughly reflected upon from different perspectives in qualitative research, the literature provides little guidance for the practical gathering and handling of multi-lingual material. As a contribution to filling this gap, the paper suggests a systematic, comparative combination of oral and written translations of interviews, which would serve both a diagnostic and a heuristic function. Based on an ethnographic study in Zambian refugee camps and conceptual distinctions between schemes of translation, I identify, in oral translations, five forms of translator's decision to depart from the literal wording in favor of a pragmatic translation intended to aid continuation of the conversation. As an important element of the suggested procedure, the comparison of the translation modes is systematically discussed with the translating research assistant, leading not only to reflection on further translation practices, but, most importantly, to an awareness of important substantial aspects of the material. This heuristic function of the comparative combination of translation modes thus leads to an enhancement of the research process.

Keywords Qualitative Interviews; Language; Translation; Ethnography; Multi-Lingual Fields; Interpreter; Refugee Camps

\begin{abstract}
Katharina Inhetveen is a Professor of so-
Katharina Inhetveen is a Professor of so-
ciology with special reference to qualitative

research methods at the Ludwig Maximilian

University of Munich. Her main research in-

terests are refugee and migration research,

political sociology, sociology of violence, so-

ciology of music, and qualitative methods.

email address:

Katharina.Inhetveen@soziologie.uni-muenchen.de :
\end{abstract} -

\section{Introduction:}

Language and Qualitative Methods

Language is at the core of most qualitative research methods. Numerous approaches are explicitly rooted in theoretical and methodological reflections that make language their primary source for social research. ${ }^{1}$ Other qualitative

${ }^{1}$ For an overview, see Knoblauch (2000). methods concentrate less on theoretically examining linguistic aspects of the social, but they nevertheless rely heavily on verbal data as their empirical material. The material of languagebased qualitative research can range from deliberately research-produced texts, such as interviews or group discussions, to data that exist independently from the research process, such as pre-existing records of "natural" conversations examined by conversation analysts, or "observed conversation," as Georg Klute (2001) calls it, in ethnography.

Interpretative approaches to social research are interested in the field participants' perspective, in their constructions of reality, the emic perspective; theoretical results are to be grounded on these reconstructions. While many qualitative methods differ widely from each other - and their exponents often fight vigorously with respect to their methodological and practical approaches, there is a broad consensus that language is of basic importance for interpretations, categories, everyday theories, and actions in the social world. Studying language, in the form of verbal material, is used as a central gateway to sociologically accessing social patterns and processes. As Peter L. Berger and Thomas Luckmann emphasize, language "is capable of becoming the objective repository of vast accumulations of meaning and experience, which it can then preserve in time and transmit to following generations" (1967:52). Accordingly, language is crucial for all methods that aim at tracing the participants' generalized patterns of meaning and experience.
Traditionally, qualitative sociologists have mostly researched social fields in the language they spoke (or seemed to speak) themselves. For a long time, problems concerning the understanding and translation of other languages have thus not been prominent in discussions on qualitative sociological methods (see also Lopez et al. 2008:1729; Enzenhofer and Resch 2011:6). It was mostly neighboring disciplines that explicitly faced and considered problems of doing research in languages which are not the researchers' mother tongue. In particular, social anthropologists take an unanimous stance: for research in a culture where the language is not the researcher's own, one has to learn the native language. This was already demanded by Bronislaw Malinowski (1972) in his early remarks on methods, where he emphasized how important it was to speak Kiriwina during his research on the Trobriand Islands. Another anthropologist, James Spradley (1979), points out that an ethnographer has to learn the native language even when it appears to be the same as the researcher's, as in his example of the sociolect of skid-row men. Without learning the native language, interpretations of the field participants can hardly be studied:

[w]hen ethnographers do not learn the language, but instead depend on interpreters, they have great difficulty learning how natives think, how they perceive the world, and what assumptions they make about human experience. (Spradley 1979:20)

Speaking the native's language seems today to be the widely accepted standard for ethno- 
graphic research, ${ }^{2}$ while interpreters are still used, especially in interview research. ${ }^{3}$

But, what is a researcher supposed to do if there is not one native language in his/her field of research, because the field itself is multi-lingual and encompasses so many languages that an ethnographer hardly has the chance to learn them all (see also Hannerz 2000:249)? Such cases of multi-lingual research fields seem to have become more frequent in the social sciences recently, for example, in international migration research, studies on world society, multi-sited ethnographies, and so on

In a multi-lingual research design, translation processes involving the cooperation of several researchers and/or interpreters become inevitable - in spite of Spradley's plausible admonition. A basic difficulty of such designs is that every translation involves an interpretation of meaning by the translator (Cappai 2003), and that the rationales of these interpretations cannot be conveyed within the research group without, again, the use of cross-language translations. While problems of cross-language translations in qualitative research have been discussed from several methodological perspectives, practical tools for dealing with these difficulties in

\footnotetext{
The question remains open, however, as to what degree many cases, the readers of an ethnography will not be able to assess how well the researcher actually speaks he native language he claims to speak. See, for exaple, Temple and Edwa

See, for example, Temple and Edwards (2002), Temple Sheridan and Storch (2009).
}

reflected way are rare. ${ }^{4}$ Ulrich Oevermann's (2008) solution to treat a translated transcript just like any other transcript might work for certain qualitative approaches, ${ }^{5}$ but fails to help with the question of how to go about integrating and systematizing translation in the research process.

In this article, I will consider methodological problems that arise in research contexts involving foreign languages, in which the researcher has the impression of not understanding anything at all. Some of the problems of translation and cross-language understanding apply to sociolects and foreign languages alike. Reflections on foreign languages in qualitative methods can thus also shed light on latent problems in seemingly monolingual research. However, a basic difference between foreign languages and sociolects in interviews seems to be that crosssociolect communications offer ways to achieve better understanding in the course of a conversation, starting from a shared grammar and vocabulary repertoire that exists in spite of "false friends" and misunderstandings (Cicourel 1974) In interviews with foreign language speakers, there are not just misunderstandings, there is no understanding at all.

${ }^{4}$ In this respect, the discussion on quantitative method is more advanced, offering quite elaborate forms of con(serce forvey reness [2003]). The translation ping and Law [2000], Harkresearch faces are, however, different in severan from those in qualitative research making it difficult to see Lopez et al 2008).

${ }^{5}$ For a more elaborate treatment of cross-language data as secondary data analysis, see Temple, Edwards and Alexander (2006).
Addressing this problem, I will suggest a procedure for dealing with translations in a specific research situation, namely in ethnographic interviews in a multi-lingual field. The suggestion aims at the practical, hands-on level of qualitative research, rather than continuing the methodological discussion on translation in multilingual research. I will outline an approach for combining two forms of translation, an oral translation during the interview and a written translation after the interview, using the recorded material. The suggested comparative combination is to be integrated in a close collaboration with local research assistants, which not only includes translating, but also discussion of questions arising from translations and, connected to this, of substantial problems in the phenomena under study.

First, I will briefly outline the research context in which the idea for this procedure was developed. Second, I will discuss the individual and the combined advantages of oral and written translations in ethnographic research. The specific benefits of combining oral and written translations encompass a diagnostic function, which allows for identifying general and translator-specific tendencies in oral translation during interviews; and a heuristic function, which brings out problematic aspects and new generic questions concerning phenomena and research problems, helpful for the further gathering and analysis of material.

\section{The Research Context}

\section{Refugee camps as a multi-lingual field}

The following comments are based on practical experiences in a research project on the political order of refugee camps (Inhetveen 2010). The fieldwork in two Zambian camps was conducted from May to November 2003. One of the camps was Meheba Refugee Settlement in Zambia's North-Western Province, with a size of $80 \mathrm{~km}^{2}$ and 42,000 refugees at the time of the research. Most of the inhabitants were Angolan, many from rural areas in the Moxico Province and without formal education - which also means they did not speak Portuguese or English, the administrative languages in Angola and Zambia respectively. Most of the material presented in this article stems from Meheba. The other camp was Nangweshi Refugee Camp in Zambia's Western Province, a classical, compact camp with 28,000 refugees at the time of the research. Practically, all the inhabitants of Nangweshi main camp had fled from Jamba in south-west Angola, the former headquarters of the rebel group UNITA, and many had gone to school there (Inhetveen 2010). Thus, I conducted a large part of the interviews directly in Portuguese, without oral translation. ${ }^{6}$

Typically, a number of specific actors are present in a refugee camp, living and working there. Especially in Meheba, the refugee population was remarkably heterogeneous, with inhabitants

${ }^{6}$ This material was also analysed in its Portuguese form. Quotations were translated only in publications, for the purpose of presentation to the readers (see the suggestion by Ummel [2008]). 
from different nations and, as far as the Angolans were concerned, different regions and language groups within Angola. Also part of the camp, and the research project, was personnel from different organizations, in particular staff from the United Nations High Commissioner for Refugees (UNHCR), the Refugee Officer (RO) as the representative of the Zambian government, and branches of several non-governmental organizations (NGOs). The agencies worked with Zambian and international staff, as well as casual workers recruited among the refugees. It was this diversity of actors that initially triggered my interest in refugee camps: the long-term involvement of different social actors in one social and organizational unit.

Considering the manifold array of actors, it came as no surprise that several languages were spoken in the research field refugee camp. While English is the administrative language in Zambia and lingua franca in the world of humanitarian organizations, the staff members and refugees had many different mother tongues. As mentioned above, a part of the Angolan refugees spoke Portuguese, and a few inhabitants of Meheba spoke English due to a Zambian school education. While the material from this research does not, by far, encompass all languages spoken in the camps, it includes at least ten of them: English, Portuguese, German, Luvale, Umbundu, Chokwe, Luchazi, Lunda, Swahili, and Bemba. I spoke English, on a few occasions German, and tolerable Portuguese, but none of the indigenous languages. In many situations, I would have been lost without an interpreter.

\section{Research methods and research situation}

My research question implied an interest no only in the refugees, but in the relationships between all the different actors in the camps. For studying the agencies that were involved, higher organizational levels were also relevant, national offices as well as international headquarters. The research project as a whole included thus, a number of research sites and methods, while the material from the camps formed the main data corpus. In Meheba and Nangweshi, I mainly conducted observations, interviews and informal conversations. In the national and international offices of organizations and government agencies, the emphasis was on in terviews and archival research, in addition to online documents that were analyzed selectively. The following discussion refers to the interviews with camp refugees and thus to only one of the methods employed in the project.

During almost all of these interviews, a local research assistant was present. In both camps, I worked with young refugees who were familiar with camp life and camp administration and who could speak a high number of languages (even for African standards, where many people are multi-lingual anyway). The research assistants fulfilled a whole array of essential tasks: in the extensive terrain of the camps, they acted as guides; they established contacts with refugees; they helped to clarify countless background questions; they interpreted during informal and observed conversations; they supported the theoretical sampling with their ideas; they discussed with me questions of interpretation for sections of the material; and they orally translated during interviews and produced written translations of selected interview recordings. These last two tasks, in their combination, will be the central theme of the following comments.

When, in this research, a single local assistant translated for a single researcher, this arrangement was connected to specific characteristics of the research situation - which it shares with many other studies. Firstly, a six-month period of field research in Africa in the course of a Europe-based research project is typically (though not necessarily) conducted by a single researcher or very small teams. Co-workers have to be recruited locally. Secondly, research in a multilingual field, such as a refugee camp, is not possible for a single person without the help of translators. ${ }^{7}$ Thirdly, most refugee camps, including Meheba and Nangweshi, are situated on the periphery of the host country. This means that professional translators with knowledge of the locally relevant languages are hard to find, and one normally works with assistants who may be experienced, but who have no formal training as translators. At the same time, the opportunities for training them as interviewers are limited when one spends only a few months in one camp. Even though a small number of peer-to-peer interviews were conducted by one

I use the term "translator" instead of the more common "interpreter" for somebody doing oral translations during conversations, in order to distinguish more clearly between the general methodological term of "interpreta"it " ways implies an act of "interpretation" in this sense. assistant in this research, a broader, more systematic application of this method would have demanded more time and resources. Lastly, one has to consider the limited technical equipment available, the difficulties of working with computers in a dusty environment with an unreliable power supply for just a few hours each day. While I would not want to complain about a research situation that was, after all, very good and altogether a pleasure to work in, the above-mentioned circumstances should be kept in mind for understanding the choice of procedures suggested in this paper.

\section{Oral and Written Translations of Interviews}

The procedure suggested in this article does not stem from the drawing board, but was an outcome of the field research depicted above. When doing interviews with refugees in the Zambian camps, I was often dependent on a translator - in this case my local research assistant. This situation was new for me and came with a fair amount of uncertainness in conversations with the interviewees and in the analysis of the interview materials. I thus asked my research assistant in Meheba for additional assistance: for selected interviews, he translated again what the refugees had said and what he had already translated orally in the interview situation. This time he translated the interviews in written form, from the audiotape, into English. This ad hoc idea proved to be methodologically useful, and the following suggestions stem partly from my practice during research in the refugee camps and partly from a systematization of 
these practices which I undertook afterwards, using materials from this project.

At first sight, the combination of an oral and a written translation may seem like an unnecessary duplication. If I employ an assistant who I think is capable and skilful, why should I ask him to translate the same interview text twice? After all, I do not work with two different translators, employing a kind of control mechanism, as is common in quantitative survey studies using questionnaires in different languages (Harkness 2003), and as Norbert Schröer (2009) has proposed recently for the hermeneutic sociology of knowledge.

The reason for this double translation lies in the potential gain from combining oral and written translations as distinctive modes of translation. While other researchers have focused on the similarities between the two (Temple and Edwards 2002), I will highlight the differences and the potential that is held by relating them to each other.

There is a consensus in social and linguistic sciences that you cannot find the correct reproduction of a statement, with identical meaning, by just picking the right semantic equivalent in another language. There is, as Schröer puts it, "no neutral set of correspondences" between languages, no "authentic" translation (2009:17-18 [translation - K.I.])

Of course, translations can be "simply wrong." If I translate pomodoro as potato, this is not due to insurmountable barriers between cultural worlds of meaning, but just a mistake. However what translations cannot be is "simply right." As becomes obvious when dealing with more complex statements, translating opens up a range of possibilities, and none of them is a straightforward one-to-one translation. The one and only right translation into another language does not exist (Cappai 2003). As a consequence, the translator has to make decisions between divergent, but equally eligible options. Manifest or latent, this choice is unavoidable.

Different criteria for adequacy can guide this choice. They can be situated along a continuum between two poles: does the translator translate as literally as possible, looking for the closest semantic equivalent? Or does one translate first of all the practical meaning of an utterance, to secure the continuation of an ongoing communication? In this sense, Thomas Scheffer (2008) distinguishes between a representative and a performative scheme of translation. While the representative scheme translates as literally as possible, the performative scheme serves, first of all, as a basis for subsequent conversational operations. Both schemes lead to "correct" translations, differing due to their divergent propositions.

The question is, then, which criteria for translational adequacy are valid in a certain situation of translational practice. In both cases, one has to put up with specific losses due to the translation process. Translating as literally as possible, on the one hand, involves the risk of distortions due to cultural differences in the use of lexically corresponding concepts. Translating the practi- cal meaning of an utterance, on the other hand, permits a greater distance from the verbal and grammatical constructions used by the speaker in the original utterance.

For oral translation during an ethnographic interview, in our case between English and an African language, the performative scheme is important. The research assistant has to translate in a way that makes sure the conversation can continue. He expresses the meaning of each utterance in a compact way that enables the linguistically excluded participants (that is, the researcher and the interviewee alternately) to grasp its content and to connect follow-up utterances to it. In doing so, the translator considers the different cultural patterns of meaning which separate researcher and interviewee, and "moves" the text "towards" the person who is to receive it - in line with a formulation used by Friedrich Schleiermacher. ${ }^{8}$ The translator thus moves away from the representative scheme, from the attempt to make a "verbatim" translation. The oral translation, following the performative scheme, is oriented towards continuing the conversational practice, and is thus functional in an interview situation.

But, the ethnographer is also interested in what has been said literally: which concepts and formulations were used, what was the sequence of the related stories and events, which parts of the assistant's words were translations and which parts were additional explanations for the researcher? Thus, I asked for a written translation

${ }^{8}$ As quoted, in German, by Cappai (2003:22) in which the representative scheme served as a benchmark for a translation as close as possible to a lexical equivalent. For this task, the translation situation after the interview is also crucial. It enables the translator to listen to or read passages repeatedly and to decide on a translation without being pressed for time, as is the case during an ongoing conversation (see also Kalina 1998:17-20).

This additional, written translation is, however, not a test of whether the oral translation was "good" or "bad," or a correction of its translational choices. While the literature on qualitative methods mostly asks at which point verbal material should be translated, orally during data gathering or in written form after transcription, I do not treat these options as alternatives. My question is not whether one of these possibilities is better; rather, I look at the advantages of their combination. This enables us to reconstruct the decisions made during oral and written translation respectively by a research assistant, and to consider them in our interpretations. I call this the diagnostic function of the combination of oral and written translation. Moreover, the differences between the two translations of the same verbal material give us clues about crucial points in the content; these, in turn, serve as starting points for additional discussions with the research assistants. I call this the heuristic function of the combination of oral and written translation

Before elaborating on these two methodical functions of a comparative combination, I want to briefly comment on the respective advantages 
of oral and written translations independently of their combination

The use of oral translation during field research goes with a number of benefits. In a multi-lingual field, it makes the researcher's participation possible in the first place. During interviews, an oral translator enables the researcher to ask follow-up questions and to request explanations in case they have difficulties comprehending what has been said. Moreover, due to the co-participation of translator and researcher in the conversation with an interviewee, the translator/local research assistant acquires information about what especially interests the researcher in the specific project, and at which points she needs further clarifications. The practice of oral translations during interviews contributes, thus, to an integration of both researcher and local assistant into the research process.

A written translation of research material after its collection has benefits as well. It provides the researcher with more precise material in the sense of being closer to a lexical equivalent of the original wording, in accordance with the representative scheme of translation. Furthermore, it offers the translator time and space for making explanations and annotations concerning linguistic questions and the phenomena that are addressed in the material. This translation commentary can be oriented towards what the research assistant has learned (for example, during oral translations in interviews) about the interests, open questions, and priorities of the research project. Unlike during oral transla- tions, these written explanations can be notated separately from the translation itself.

The respective advantages of oral and written translations have led to a widespread separate use of these two forms of translation in qualitative research. Obviously, combining both also offers the advantages of both. The question addressed in the following considerations, however, is concerned with the possible increase of advantages gained by such a combination, exceeding the sum of the individual benefits offered by each part.

\section{The Diagnostic Function of Combining Oral and Written Translations}

The diagnostic function of combining the two forms of translation helps us to discern what actually happens during oral, rather than written, translation. The comparative combination sheds light on the decisions the translator makes during each translation process. This applies to general tendencies in oral versus written translation, as well as to the individual inclinations of a specific translator. Thus, the comparative combination of translations provides the team with important information for the research project.

Comparing oral and written translations of interviews from Zambian refugee camps, I identify, in the oral translations, five forms of translator's decision to depart from the closest orientation towards literal wording, that is, the representative scheme. Before discussing these on the basis of examples, I would like to repeat that the research assistants were not profes- sional interpreters, who would have a whole array of systematic translational instruments at their disposal. At the same time, however, the research assistants possessed a great amount of local knowledge relevant to the phenomena under study, which an external interpreter would lack. This knowledge, and awareness of the researcher's interest in it, also influences the translation process.

A first form of departing from the representative scheme consists in the translator add-

Table 1. Written and oral translation of an answer of Mr. Samukonga Chinyemba (SC), Luvale to English.

\begin{tabular}{|l|l|}
\hline \multicolumn{1}{|c|}{ written translation } & \multicolumn{1}{c|}{ oral translation } \\
\hline $\begin{array}{l}\text { SC speaking: Those who have cases when they } \\
\text { go there, they tell us when they come back. They } \\
\text { don't come to tell us about him. }\end{array}$ & $\begin{array}{l}\text { Translator speaking for SC: Those who go for } \\
\text { their meetings, the, they, they bring information } \\
\text { and they talk about him that, as the RO, but no } \\
\text { one has ever presented him to us as the one who } \\
\text { kee-, who, who keeps us here in the Settlement, } \\
\text { we've never been presented to him. }\end{array}$ \\
\hline
\end{tabular}
Source: self-elaboration

The quotation is part of the answer to my question whether the interviewee knows the Refugee Officer (RO), the Zambian government representative in the camp, if he would recognize his face. While the written translation conveys a rather short answer, the oral translation is considerably longer. It contains commentary which is not recognizably set apart from the translation. The translator identifies, firstly, the two pronouns "they" in the two sentences of the written translation as different actors. The first "they" denotes refugees who go to the RO's of- ing explanations for the researcher's benefit. The translating research assistant explains to the researcher what the interviewee has said. These explanations are not always explicitly indicated, and in an interview situation they can be hard to tell apart from the translation in the strict sense.

This is the case, for example, when pronouns used by the interviewee are replaced by names or job titles, as in the following passage (see Table 1): refugees about it. The "they" in the second sentence denotes, according to the oral translation, the camp administration, which could have introduced the RO to the refugees - who often refer to camp administration as "they" or "those who are keeping us" (Luvale: vakiku vatulama). The translator mentions the RO explicitly to the researcher, who is the addressee of the translation, and explains to her that it is the $\mathrm{RO}$ who takes care of the refugees in the camp. 
Another version of this first form of translator's decision consists in adding an explanation, based on local knowledge, to a personal name which has been mentioned. A refugee might, for example, mention a certain Mr. Lumba, and the research assistant might add in his translation that Mr. Lumba was a former RO in the camp, who now lives somewhere else.

While such added explanations are often difficult to separate from the translated representation of what has been said, the second form of the translator's decision is clearly designated. It consists in the translator's explicit interpretation of what the interviewee has said or seemed to intend. The following example is

taken from the same interview as the previous one, a conversation with SC. This handicapped refugee lives in the "home for the aged," which consists of a living area with the usual clay houses, and gets some extra support and attention from the camp's "Social Services." In one section of the interview, I wanted to know which staff members of humanitarian organizations are known to SC. The research assistant translated my question as follows question in Luvale): "How about those of the $\mathrm{UN}$, of the UN, do you know them, have you ever seen them?" The following table shows the written and the oral translation of the interviewee's answer (see Table 2):

Table 2. Written and oral translation of an answer by SC, Luvale to English

\begin{tabular}{|l|l|}
\hline \multicolumn{1}{|c|}{ written translation } & \multicolumn{1}{c|}{ oral translation } \\
\hline $\begin{array}{l}\text { SC speaking: This UN, which guards us, the } \\
\text { one at the administration? Those we know them } \\
\text { well because they, they came to chat with us. }\end{array}$ & $\begin{array}{l}\text { Translator speaking for SC: [waka?] UN, ahm, } \\
\text { Ithink, it's, it will bea bit difficultbecause there's, } \\
\text { there's a problem to distinguish between UN } \\
\text { and LWF, yeah, yeah. They know LWF because } \\
\text { they are the ones who take care of them, they } \\
\text { see them, yeah, but they, it's difficult to know } \\
\text { the distinction between UNHCR and LWF. }\end{array}$ \\
&
\end{tabular}

Source: self-elaboration

The written translation represents a relatively short answer: We (the refugees) know the United Nations, which are running the camp, well, because they came to talk to us in the living areas.

In the oral translation during the interview, the research assistant barely starts translating interviewee in actual fact is not referring to the $\mathrm{UN}$, but to LWF, which is an NGO working in Meheba. The translator explains this error on the part of the refugee by pointing out that it is LWF Social Services staff who come to the in(as confirmed by the written translation of his

terviewee's living area, and that it is often difficult for the camp inhabitants to differentiate between staff members of the different organizations. In the written translation, there is no indication of a possible mix-up of the visiting agency staff.

In the further course of the research, this phenomenon, for example, that refugees could rarely identify the agency staff working in and making decisions for the camp, became central for interpreting the relations between camp administration and refugees (Inhetveen 2010).

A third form of the translator's decision during oral interpretation consists in the implicit interpretation of meaning by employing a more specific vocabulary than the interviewee has used. An example is the research assistant in Nangweshi, who always translated the Um-

Table 3. Written and oral translation of an answer by NM, Chokwe to English.

\begin{tabular}{|c|c|}
\hline written translation & oral translation \\
\hline $\begin{array}{l}\text { NM speaking: When they found me there at } \\
\text { home, they went straight into catching goats } \\
\text { and chicken, the soldiers, and I was alone with } \\
\text { only a child at home. They caught the goats, and } \\
\text { only gave me twenty ngwee. It's only twenty } \\
\text { ngwee. All those goats and chickens that filled } \\
\text { the vehicle. And they just got a twenty ngwee } \\
\text { and gave me. }\end{array}$ & $\begin{array}{l}\text { Translator speaking for NM: Soon as they } \\
\text { dropped from the vehicle, they started chasing } \\
\text { animals, goats and chicken, caught them, put } \\
\text { them in the vehicle and gave her a coin. }\end{array}$ \\
\hline
\end{tabular}

bundu word meaning "war" in general as "civil war" when interviewees talked about the conflict between MPLA and UNITA in Angola. This tacit interpretation leads to an increased detailedness of the resulting research material, that is, the translated interview text in relation to the wording of the interviewee.

The opposite is the case in the fourth form of the translator's decision, which consists in a resumptive interpretation of meaning. By summing up an interviewee's statements during the oral translation, the detailedness of the resulting text is decreased. In the following example, an old refugee woman, Nene Muswema (NM), tells us about the situation that led to her flight from Angola. This was during colonial times, when a vehicle full of white, armed soldiers appeared at her home (see Table 3):
The translator sums up NM's story about colonial soldiers invading and robbing her home, a situation which continued and finally made her flee to Zaire. By retelling and summing up the rough course of events, he omits, among other things, the repetitions in the text. $\mathrm{He}$ 
leaves out the situation that the interviewee was at home alone with her child, in this case the repetition of information that she had given earlier. He also omits the repeated naming of the small value of the coin she was given. By this omission, the drama expressed by these repetitions is lost: the mismatch between the little coin and the whole vehicle full of animals stolen by the soldiers. ${ }^{9}$ The oral translation contains, thus, less detail about the recounted events and about the interviewee's evaluation of them.

The fifth form of the translator's decision consists in adaptation to sociolects that are relevant in the field or in the work of a research assistant. This might be, for example, the humanitarian speak that pervades refugee aid organizations, or what is perceived as social science lingo, or the sociolect and individual

habits of the researcher with her personal background. ${ }^{10}$ Such adjustments or adaptations to sociolects have the tendency to lead the translation away from the representative scheme, as do adaptations to general conventions in the target language when a more literal translation would seem awkward to the translator. The following example of such adaptive processes stems from an interview with the Angolan Chief Toh Muzala Likonge, a refugee in Meheba (see Table 4).

In the oral translation of CL's answer, the assistant uses the English expressions the researcher used: he reverts to the expression "leader" which I used in my question. For the interviewee, he translates the English concept of "leaders" into a Luvale concept approximating "elders." In his answer, the interviewee also uses a more specific and differently connoted expression approxi-

Table 4. Written and oral translations from an interview by the author (KI) with Chief Likonge (CL) English to Luvale and Luvale to English.

\section{written translation}

KI speaking: And how is it in Meheba, for the Translator speaking for KI: Regarding our area whole settlement, who has the power and can here in Meheba, who is the elder [leader] of our make the decisions for the whole settlement, area of Meheba, who makes decisions for all of who is the most superior leader here?

CL speaking: Eh, here in Meheba, RO is the Translator speaking for CL: Here in Meheba it is elder who guards us. He is the one we stay with the $\mathrm{RO}$ who is there, who takes care of us, he is here.

\section{Source: self-elaboration}

In his written translation, the research assistant adds the information that ngwee is in fact a unit of the Zambian, not the Angolan currency - a hundredth of one Zannian kwacha and used any more. of such "transtation competence" a Spradley (1979:19-21, 52-54) mating "elder," which the research assistant again translates into English as "leader." In the written translation, he stays closer to the representative scheme, using the word "elder." In his written back-translation of his own question in Luvale, he includes a note in brackets about the transformation in the oral translation and thereby informs me about it. This translation problem concerning the concepts "elder" and "leader" is prevalent also in other interview sections, and it shows how translators have to decide between translation options none of which is an exact equivalent of the original expression. This led to comprehensive discussions about translations and variations in the semantic field of "leader" and, similarly, of "government," a concept which has several different translation options in Luvale. Results and shared knowledge arising from these discussions can enhance the translation process during further interviews.

Different forms of translational adaptations are also known in comparative quantitative research. They are purposefully employed in translations of survey questionnaires (Harkness, Van de Vijver and Johnson 2003). In the case of adaptations in the oral translation of an ethnographic interview, however, the implicit adaptive practices have to be identified in the first place. For this task, the comparison of oral and written translations can serve as a diagnostic tool.

The five forms of the translator's decision in oral translation, which I identified in my research in Meheba do not represent an exhaustive list. In other fields and with other translators, there will be different forms prevalent.
However, each identified tendency that occurs in such translations can also be instructive for the handling and examination of translations in other research contexts. When such forms of departing from the representative scheme in oral translations are explicitly identified, they often remain useful within the performative scheme, which is dominant in the interview situation. At the same time, since they are now open to discussion and consideration, they will not impair analysis of the resulting material (while, for example, an unidentified translator's commentary might be mistaken for an utterance by an interviewee)

\section{The Heuristic Function of Combining Oral and Written Translations}

From the diagnosis of implicit translation decisions, a heuristic benefit can be gained for the progressing research. This is facilitated by a further methodological step, namely systematic discussions with the translating research assistants about the comparison between the oral and the written translation of an interview.

Such discussions provide an opportunity to talk about the translation tendencies of the assistant, maybe encouraging some of them and abating others, and, most importantly, to take them into account during analysis of the material. In addition, and no less importantly, these discussions point to semantic fields and phenomena that are

${ }^{11}$ Systematic discussions and/or interviews with the translator are also part of other suggestions concerning how to handle translations in different methodologica (2002) Temple and Young (2004), Schröer (2009). 
connected with obviously difficult translation decisions. These are fields of vocabulary and phenomena which repeatedly turn out to be of importance for the research project. In the case of the present research project, some of the biggest translation problems existed at the contact points between refugees and staff members, the interface between the life worlds of the camp inhabitants and the organizations of the international refugee regime. More generally, oral and written translations produce different types of data, each of them consisting of text that is translated in a specific mode, following a specific scheme. Similar to a triangulatory procedure, the comparative combination of these texts brings out more facets of the phenomena at hand, and accentuates the discrepancies that are inevitably produced by the different modes of translating the same verbal material. Analyzing these discrepancies then facilitates differentiation of the research problem and the formulation of hypotheses. ${ }^{12}$

In my research on refugee camps, the comparisons and discussions also led to further questions that were pursued during later phases of the research. I have mentioned two examples: firstly, the question of concepts and perceptions of those who have power in the camp; and, secondly, the extreme vagueness in the refugees' perceptions of the camp administration and its

${ }^{12}$ I would like to thank Kurt Beck for pointing out this similarity to triangulation. In the context at hand, the most relevant function of those methods outlined by Uwe Flick (2000) would be triangulation as a way to additional findings - as is also the case with regard to the ployed in this research project on refugee camps. organizations - which in turn has major consequences for the political order of the camp and the refugees' position in it.

The benefits of a comparative combination of oral and written translations can thus be summed up as follows: information is gained about general and translator-specific tendencies in oral versus written translations, which then can be taken into consideration in the progressing research (diagnostic function); and information is gained about problematic semantic fields and phenomena, which can then, in a form of theoretical sampling (Strauss and Corbin 1990), be followed up in the further gathering and analysis of field material (heuristic function). The comparison between the two translation modes and discussion of them with the translating research assistants thus serves to generate further substantial questions and considerations, and creates new perspectives for further encounters with the field in observations and conversations.

\section{Concluding Remarks}

It has to be emphasized that the comparative combination of oral and written translations does not claim to solve the basic problems of translation in empirical research. A written translation from the audiotape is no more "original" then the oral translation during the interview. But, at least, a comparison of the two translations can make us observant with regard to some problematic points in the translation process. These are then open for further discussion and interpretations.
I have only dealt with one methodological problem of qualitative research in a multi-lingual field: the problem of the translator's decisions made by research assistants. There are many more and manifold problems connected with the translation of verbal material, which exceed the mere translation of words and sentences - as Joachim Matthes (1985) showed 25 years ago in his critical discussion of intercultural research using narratological methods. General problems of translation between languages can be, and have been, discussed in a methodological perspective. With respect to concrete practical options of integrating translations in qualitative research designs, the literature does not offer many guidelines or suggestions. The specific difficulties of how to handle translation challenges in qualitative research practice obviously depend, to a large degree, on the specific methods employed, both in the collection and the analysis of material. For example, methods of sequential analysis as those Matthes (1985) and Schröer (2009) refer to, aiming at discovering latent structures in the text, differ from research approaches that are primarily interested in the manifest meaningfulness of what has been said (without, however, ignoring the way it has been said). It seems that the more microscopic the analytical gaze at the verbal utterances is, the greater are the problems connected to translation processes - with their necessary transformations in the finegrain structure of the material. Concrete ways of handling translation challenges will always require an assessment of their adequacy in the specific methodological context.
But, regardless of the methodological standpoint and any reflected and systematic practical solutions: ethnographic research in a multi-lingual field will always expose methodological weak spots. A Babylonian confusion of languages can rock most methodological ivory towers. Considering these fundamental problems, what could be their consequence for our research practice and agenda?

If we shy away from research in multi-lingual fields because of methodological problems, certain topics can hardly be researched. At the same time, a number of these topics seem to be gaining importance in social research, such as international migration, transnational networks, international organizational regimes, and many more (see also Hannerz 2000:249-250). For example, a great part of the research in and on Africa, a continent rich with multi-lingual fields, would be affected. From my viewpoint, it is clear that to simply ignore the respective research fields cannot be the solution for the translation challenges they imply.

Thus, we should go about such research while trying to deal with its methodological problems in an attentive and reflective way. We are not going to solve them in the strict sense, but we can factor them in more systematically. The comparative combination of oral and written translations in ethnographic interviews, which I have proposed in this article, hopefully contributes to this task. 


\section{Acknowledgements and Credits}

Comments by participants of the ESA Midterm Conference 2010, by seminar participants at the Universities of Siegen, Munich and Bayreuth and by the reviewers are gratefully acknowledged. Special thanks go to the local research assistants who worked with me in the field, André Joaquim Melo and Hildah Njamba.

\section{References}

Behling, Orlando and Kenneth S. Law, (ed.). 2000. Translating Questionnaires and Other Research Instruments: Problems and Solutions. Thousand Oaks: Sage.

Berger, Peter L. and Thomas Luckmann. 1967. The Social Construction of Reality. Harmondsworth: Penguin.

Cappai, Gabriele. 2003. “Einleitung: Übersetzung zwischen Kulturen als interdisziplinäre Aufgabe." Pp. 11-29 in Sozialwissenschaftliches Übersezzen als interkulturelle Hermeneutik / Il tradurre nelle scienze sociali come ermeneutica interculturale, edited by A. Zingerle, G. Cappai. Milano, Berlin: Angeli/Duncker \& Humblot.

Cicourel, Aaron V. 1974. Methode und Messung in der Soziologie. Frankfurt am Main: Suhrkamp.

Enzenhofer, Edith and Katharina Resch. 2011. “Übersetzungsprozesse und deren Qualitätssicherung in der qualitativen Sozialforschung." Forum Qualitative Sozialforschung / Forum: Qualitative Social Research 12(2), Art. 10. Retrieved January 29, 2012 (http://nbnresolving.de/urn:nbn:de:0114-fqs1102106).

Flick, Uwe. 2000. “Triangulation in der qualitativen Forschung." Pp. 309-318 in Qualitative Forschung. Ein Handbuch, edited by U. Flick, E. V. Kardorff and I. Steinke. Reinbek bei Hamburg: Rowohlt.
Hannerz, Ulf. 2000. "Transnational Research." Pp 235-256 in Handbook of Methods in Cultural Anthropology, edited by H. R. Bernard. Walnut Creek, Lanham, New York, Oxford: AltaMira.

Harkness, Janet. 2003. "Questionnaire Translation." Pp. 35-56 in Cross-Cultural Survey Methods, edited by J. A. Harkness, F. J. R. Van de Vijver and P. Ph Mohler. Hoboken, NJ: Wiley.

Harkness, Janet, Fons J. R. Van de Vijver and Timothy P. Johnson. 2003. "Questionnaire Design in Comparative Research.” Pp. 19-34 in Cross-Cultural Survey Methods, edited by J. A. Harkness, F. J. R. Van de Vijver and P. Ph. Mohler. Hoboken, NJ: Wiley.

Inhetveen, Katharina. 2010. Die politische Ordnung des Flüchtlingslagers. Akteure - Macht - Organisation. Eine Ethnographie im Südlichen Afrika. Bielefeld: Transcript.

Kalina, Sylvia. 1998. Strategische Prozesse beim Dolmetschen. Theoretische Grundlagen, empirische Fallstudien, didaktische Konsequenzen. Tubingen: Narr.

Klute, Georg. 2001. “Die Rebellionen der Tuareg in Mali und Niger." Unpublished Habilitation thesis, Faculty of Humanities and Social Sciences, Siegen University, Siegen.
Knoblauch, Hubert. 2000. "Das Ende der linguistischen Wende. Sprache und empirische Wissenssoziologie." Soziologie, Heft 2:46-58.

Lopez, Griselda I., Maria Figueroa, Sarah E. Connor et al. 2008. "Translation Barriers in Conducting Qualitative Research With Spanish Speakers." Qualitative Health Research 18:1729-1737.

Malinowski, Bronislaw. 1972. Argonauts of the Western Pacific. London: Routledge \& Kegan Paul.

Matthes, Joachim. 1985. “Zur transkulturellen Relativität erzählanalytischer Verfahren in der empirischen Sozialforschung." Kölner Zeitschrift für Soziologie und Sozialpsychologie 37:310-326.

Sheridan, Vera and Katharina Storch. 2009. “Linking the Intercultural and Grounded Theory. Methodological Issues in Migration Research." Forum Qualitative Sozialforschung / Forum: Qualitative Social Research 10(1), Art 36. Retrieved February 2, 2012 (http:// nbn-resolving.de/urn:nbn:de:0114-fqs0901363).

Spradley, James P. 1979. The Ethnographic Interview. New York: Holt, Rinehart and Winston.

Strauss, Anselm and Juliet Corbin. 1990. Basics of Qual itative Research. Grounded Theory Procedures and Techniques. Newbury Park, London, New Delhi: Sage.

Temple, Bogusia and Rosalind Edwards. 2002. “Interpreters/Translators and Cross-Language Re-

Oevermann, Ulrich. 2008. “Zur Differenz von praktischem und methodischem Verstehen in der ethnologischen Feldforschung - Eine rein textimmanente objektiv hermeneutische Sequenzanalyse von übersetzten Verbatim-Transkripten von Gruppendiskussionen in einer afrikanischen lokalen Kultur." Pp. 145-233 in Forschen unter Bedingungen kultureller Fremdheit, edited by G. Cappai. Wiesbaden: VS Verlag.

Scheffer, Thomas. 2008. “Mehrsprachigkeit in qualitativen Forschungsdesigns." Paper presented at a workshop of the DGS section Methoden der qualitativen Sozialforschung, November 28, Siegen, Germany.

Schröer, Norbert. 2009. "Hermeneutic Sociology of Knowledge for Intercultural Understanding." Forum Qualitative Sozialforschung / Forum: Qualitative Social Research 10(1), Art 40. Retrieved February 2, 2012 (http://nbn-resolving.de/urn:nbn:de:0114fqs0901408). search: Reflexivity and Border Crossings." International Journal of Qualitative Methods 1(2):1-12.

Temple, Bogusia and Alys Young. 2004. “Qualitative research and translation dilemmas." Qualitative Research 4(2):161-178

Temple Bogusia, Rosalind Edwards and Claire Alexander. 2006. "Grasping at Context: Cross Language Qualitative Research as Secondary Qualitative Data Analysis." Forum Qualitative Sozialforschung / Forum: Qualitative Social Research 7(4), Art 10. Retrieved September 8, 2009 (http://nbnresolving. de/urn:nbn:de:0114-fqs0604107)

Ummel, Hannes. 2008. "Implikationen von «Einszu-eins-Übersetzungen» vom schweizerdeutschen Dialekt ins Deutsche." Paper presented at a workshop of the DGS section Methoden der qualitativen Sozialforschung, November 29, Siegen, Germany. 